\title{
RECOMENDACIONES PRÁCTICAS PARA LA ANTISEPSIA Y DESINFECCIÓN
}

(Practical recommendation for antisepsis and disinfection)

Fernando Moreno ${ }^{1 *}$, Ankie Schade ${ }^{1}$, Pamela Rivero ${ }^{1}$, Cristian Smith ${ }^{1}$. 1.Unidad de Prevención y Control de Infecciones Asociadas a la Atención de Salud. Hospital Carlos van Buren de Valparaíso.

*Autor para correspondencia: infeccionesintra.hcvb@redsalud.gov.cl

RECIBIDO: 15 de Octubre de 2015 APROBADO: 17 de Noviembre de 2015

LOS AUTORES DECLARAN NO TENER CONFLICTO DE INTERESES

Palabras clave: control y prevención IAAS, recomendaciones.

Key words: control and prevention of infections associated with health care, recommendations.

\section{RESUMEN}

Se presenta una breve revisión de los antisépticos y desinfectantes mas comunes, su utilidad, la forma de aplicarlos y de almacenamiento en los distintos servicios hospitalarios. Además se incluye el manejo, limpieza y aseo de las distintas áreas clínicas.

\section{INTRODUCCIÓN}

La antisepsia y desinfección, en conjunto con la esterilización, constituyen las medidas que contribuyen efectivamente al control y la prevención de las infecciones asociadas a la atención de salud (IAAS) (1).

\section{Definiciones}

Limpieza: es la eliminación por acción mecánica, con o sin uso de detergentes, de la materia orgánica y suciedad de superficies, objetos o ambiente.

Desinfección: es la destrucción de microorganismos en objetos inanimados que aseguran la elimi-

\begin{abstract}
The present manuscript introduces a short revision of most commonly antiseptic and disinfectant used in health services, includes its utility, way to use and storage. Furthermore adds the management and cleaning of the multiple clinical areas.

nación de las formas vegetativas, pero no la eliminación de esporas bacterianas.

Desinfectante: agente químico utilizado en el proceso de desinfección de objetos y superficies.

Antiséptico: agente químico utilizado en el control de microorganismos de la piel u otro tejido vivo.

Esterilización: es la eliminación completa de toda forma de vida microbiana que puede obtenerse a través del uso de métodos químicos o físicos.

Microbiota residente: son los microorganismos presentes permanentemente en la piel de la mayoría de las personas, los cuales no pueden ser erradicados en forma definitiva.
\end{abstract}


Recomendaciones practicas para la antisepsia y desinfección - F. Moreno et al.

Microbiota transitoria: corresponde a microorganismos presente en algunas personas, que no se mantienen necesariamente en el tiempo, habitualmente bacterias patógenas $\mathrm{u}$ oportunistas del ambiente intrahospitalario.

\section{Niveles de desinfección}

Alto Nivel: elimina las formas vegetativas de las bacterias, bacilos de la tuberculosis, esporas, hongos y virus. No destruye priones.

Intermedio: actúa sobre todas las formas vegetativas de los microorganismos, exceptuando las esporas y priones.

\section{Antisépticos}

Un antiséptico es un tipo de compuesto químico que cuando se aplica a la superficie corporal, destruye o inhibe el crecimiento de microorga- nismos, sin causar efecto nocivo. Los antisépticos están diseñados para ser usados en piel y algunas mucosas (1).

El uso de los antisépticos se requiere en los casos que se desee reducir, inhibir o eliminar microorganismos que colonizan la piel y deben ser usados siempre en los siguientes casos:

1. Lavado de manos antes de realizar un procedimiento invasivo

2. Lavado de manos quirúrgico

3. Preparación preoperatoria de la piel

4. Preparación de la piel para instalación de procedimientos invasivos

Para que un antiséptico sea útil debe reunir ciertas características como lo son: amplio espectro, acción rápida, fácil de formular, no tóxico, no irritante de piel ni mucosas, que tenga un efecto acumulativo y residual, con baja inactivación por materia orgánica y de bajo costo.

Tabla1. Propiedades de diferentes antisépticos.

\begin{tabular}{|l|c|c|c|}
\hline \multicolumn{2}{|c|}{ PROPIEDADES DE DIFERENTES ANTISEPTICOS } \\
\hline Propiedades & Alcohol etílico & Clorhexidina & Povidona yodada \\
\hline Espectro & Amplio & Amplio & Bacterias, virus \\
Micobacterias & $\mathrm{Si}$ & No & No \\
Inicio acción & Inmediato & $>3$ minutos & Intermedio \\
Efecto residual & Ninguno & Maximo, $>6$ hrs & Baja \\
Toxicidad & Irritante sobre mucosas & Baja & Intermedio \\
Costo & Económico & Alto & Contraindicado en caso alergia \\
Otros & Inflamable & & \\
\hline
\end{tabular}

\section{Desinfectantes}

Es un agente químico usado en superficies ambientales, pisos y artículos médicos para eliminar microorganismos (2).

\section{Proceso de desinfección}

Un proceso de desinfección elimina la mayoría de los microorganismos, pero no necesariamente las esporas bacterianas. Con el 
tiempo suficiente de exposición y bajo condiciones específicas, algunos desinfectantes pueden también eliminar esporas, y por ello son considerados esterilizantes.

Lo primero que se debe realizar con los artículos es lavar prolijamente antes de realizar la desinfección, pues la presencia de sustancia orgánica como sangre y fluidos corporales, puede evitar el contacto del desinfectante con la superficie de los dispositivos.

\section{Recomendaciones generales}

No realizar la preparación y/o fraccionamiento de las soluciones antisépticas y desinfectantes en los servicios clínicos.

Los desinfectantes y antisépticos deben usarse respetando las instrucciones del fabricante respecto a duración del producto, condiciones de conservación, tiempo de contacto y dilución. No es recomendable hacer mezclas para su uso.

\section{Almacenamiento}

1. Los frascos de antisépticos y desinfectantes deben ser almacenados en un lugar destinado exclusivamente para ello, protegido del polvo, la contaminación y a temperatura ambiente.

2. Una vez abiertos los frascos, no podrán volver a guardarse en el mismo sitio.

3. Durante el tiempo de almacenamiento, deben permanecer sellados.

4. Debe evitarse mantener stock en los Servicios Clínicos. Si se hace, debe ser pequeño.

5. Siempre deberán almacenarse los frascos de acuerdo a su fecha de vencimiento y su salida será dando prioridad a aquellos con mayor tiempo de almacenamiento.

\section{Recomendaciones sobre el uso de antisépticos $(3,4,5,6)$.}

- En los frasco de antisépticos deberá colocase la fecha de apertura en la etiqueta.

- En caso de que se encuentre abierto, verificar vigencia del producto.

- No debe almacenarse excedentes o remanentes de antisépticos para días posteriores.

- Los antisépticos que encontrándose abiertos no tengan fecha de apertura en envase, se considerarán vencidos. Los antisépticos no se deben trasvasar, ni rellenar en ninguna área del Hospital.

- No se deben aplicar sobre la piel dos o más agentes químicos simultáneamente, ya que se altera su acción.

Los antisépticos siempre se aplican en superficies sobre las cuales se ha hecho previamente una limpieza por arrastre ya que se inactivan en presencia de materia orgánica.

- Las tórulas que se usan para antisepsia de la piel, en la administración de medicamentos, deben impregnarse con la solución antiséptica al momento de realizar el procedimiento para evitar la contaminación y evaporación del producto. No se deben preparar tórulas con antiséptico en forma previa.

- Cuando se utilice el antiséptico en grandes superficies cutáneas, hay que considerar el grado de absorción y la posible toxicidad sistémica.

- Los antisépticos no deben usarse para la limpieza de superficies, material de uso clínico o instrumental. Este procedimiento debe realizarse con agua y detergente.

- Se acepta el uso de alcohol $70^{\circ}$ para su utilización 
Recomendaciones practicas para la antisepsia y desinfección - F. Moreno et al.

como desinfectante en superficies de fonendoscopios, termómetros, teclados de PC y otros equipos médicos

- Tapar los antisépticos y desinfectantes con su tapa original. Nunca se deben tapar utilizando cubiertas de metal, algodón, gasa, corcho o papel.

\section{Recomendaciones sobre el uso de desinfectan-} tes $(3,4,5,6)$.

- Los desinfectantes sólo se pueden utilizar sobre superficies y material inanimado. El único desinfectante con actividad como antiséptico es el alcohol.

- Para que tengan efectividad, deben ser aplicados sobre superficies u objetos previamente limpios.

- Se recomienda usar solamente las diluciones recomendadas por el fabricante y esta guía.

- El operador debe usar protección: guantes, mas- carilla y antiparras al momento de la dilución de los desinfectantes.

- Mantener envases cerrados.

- Las soluciones de cloro no deben ser usado más allá de 24 hrs. Posteriormente se debe eliminar el remanente ya que las concentraciones de cloro disponible, disminuyen con el paso de las horas por la evaporación.

- Los recipientes o baldes donde se preparan las soluciones desinfectantes deben estar previamente limpios y secos.

- Los desinfectantes deben diluirse de acuerdo a las recomendaciones del fabricante, estas deben ir con rótulo que contenga los siguientes datos: Nombre del funcionario que diluye, porcentaje de dilución y fecha.

- No deben mezclarse en un mismo recipiente desinfectantes de distinta composición. Controlar la fecha de vencimiento de los desinfectantes.

Tabla2. Cuadro comparativo desinfectantes.

\begin{tabular}{|l|c|c|c|}
\hline \multicolumn{3}{|c|}{ Cuadro comparativos desinfectantes } \\
\hline Desinfectantes & Clorados & Amonios cuaternarios & + \\
Toxicidad & ++ & + & - \\
Corrosión & +++ & - & +++ \\
Amplio espectro & +++ & ++ & +++ \\
Inactivación materia orgánica & +++ & +++ & ++ \\
\hline
\end{tabular}


Recomendaciones practicas para la antisepsia y desinfección - F. Moreno et al.

Tabla 3. Cuadro comparativo uso de desinfectantes.

\begin{tabular}{|l|c|c|c|}
\hline \multicolumn{4}{|c|}{ Cuadro comparativo uso de desinfectantes } \\
\hline & Clorados & Amonios cuaternarios & alcohol \\
\hline Pisos En General & + & ++++ & - \\
Sanitarios & +++ & +++ & - \\
Áreas Criticas & +++ & + & + \\
Mobiliario & ++ & ++ & ++ \\
Equipo & - & + & ++ \\
Medicamentos & - & - & ++ \\
\hline
\end{tabular}

Diluciones recomendables del cloro

- Solución clorada al $0.5 \%$ debe ser utilizada en situaciones puntuales, tales como pacientes con diarrea por Clostridium difficile o Rotavirus.
- Solución clorada al $0.1 \%$ permite limpieza de superficies, pisos y equipos cuando no es posible utilizar un amonio cuaternario.

Tabla 4. Preparación de soluciones cloradas.

\begin{tabular}{|c|c|c|c|c|c|}
\hline \multicolumn{3}{|c|}{ Preparación solución clorada $0.1 \%$} & \multicolumn{3}{|c|}{ Peparación solución clorada $0.5 \%$} \\
\hline Agua & Cloro & Cantidad & Agua & Cloro & Cantidad \\
\hline $980 \mathrm{ml}$ & $20 \mathrm{ml}$ & 1 litro & $900 \mathrm{ml}$ & $100 \mathrm{ml}$ & 1 litro \\
\hline $4900 \mathrm{ml}$ & $100 \mathrm{ml}$ & 5 Litros & $4500 \mathrm{ml}$ & $500 \mathrm{ml}$ & 5 litros \\
\hline
\end{tabular}

La preparación debe ser cambiada cada 24 horas

\section{Manejo de las áreas clínicas}

El manejo de las áreas clínicas permite una mejor organización de los servicios clínicos y facilitar las actividades con el buen uso de clínicas y estaciones de enfermería o áreas administrativas, y así prevenir y controlar infecciones intrahospitalarias en pacientes y funcionarios.

\section{Definición de las diferentes áreas}

Área limpia: lugar donde se almacenan insumos, materiales, equipos y medicamentos para la atención de los enfermos y además se realizan procedimientos limpios o estériles, como la preparación de medicamentos y soluciones, por ejemplo: clínica de enfermería. 
Recomendaciones practicas para la antisepsia y desinfección - F. Moreno et al.

Área sucia: lugar de almacenamiento transitorio de basuras, ropa sucia y lavado de material sucio/ contaminado. Se debe ubicar físicamente separada del área limpia y del área administrativa.
Estación de enfermería: físicamente separada de las dos anteriores, es el lugar para realizar labores administrativas y mantener insumos de escritorio, fichas, radiografías, manuales, normas, etc.

Tabla 5. Actividades a realizar en áreas de la clínica de enfermería

\begin{tabular}{|c|c|c|}
\hline & Área limpia & Área sucia \\
\hline • & Lavado de manos & - Lavar material previo envío a esterilización \\
\hline • & Preparar medicamentos & - Almacenar transitoriamente material sucio \\
\hline • & Almacenar medicamentos & - Dejar transitoriamente muestras de exámenes \\
\hline - & Almacenar material estéril o limpio & - Eliminar desechos y material cortopunzante \\
\hline - & $\begin{array}{l}\text { Eliminar desechos no contaminados } \\
\text { (toalla desechable, papeles, etc.) }\end{array}$ & \\
\hline
\end{tabular}

\section{Características de la estación de enfermería}

- El área administrativa o estación de enfermería es la dependencia destinada para labores administrativas y la vigilancia de los pacientes, debe permitir la visualización y el acceso fácil a estos, en este lugar también se puede encontrar la central de monitorización si es que la tiene.

- Puede disponer de un lugar físico especial o formar parte de otra área. También puede estar ubicada en un sitio de tránsito como pasillos amplios.

- Se destina solo a procedimientos de tipo administrativo tales como mantención o preparación de tarjetero, fichas clínicas o registros de enfermería.

- En este sitio solo se deben almacenar formularios o artículos de oficina en general y no se puede almacenar elementos de uso clínico, alimentos, bebidas, entre otros.

\section{Limpieza y aseo de las distintas áreas}

\section{Superficies horizontales}

- El personal auxiliar de servicio utilizará los elementos de protección adecuados de acuerdo con protocolo local.

- Para las superficies y el suelo, primero se realizará la limpieza con agua y detergente.

- A continuación se aplicará el desinfectante amonio cuaternario. En caso que el paciente estuviese con precauciones de contacto se prefiere solución clorada $0.5 \%$.

- Dejar secar. 
Recomendaciones practicas para la antisepsia y desinfección - F. Moreno et al.

\section{Material y equipamiento médico}

- Los soportes de sueros, mobiliario, etc., que se encuentran en el interior de la habitación, después de limpiarlos, se desinfectaran con un paño desechable impregnado con amonio cuaternario.

\section{Importante}

Para la desinfección de las superficies metálicas no está indicada la solución clorada, ya que, por su carácter oxidante, puede causar daños en este tipo de material. En este caso se recomienda utilizar un paño húmedo impregnado con cualquiera de los otros desinfectantes señalados.

\section{Aseo terminal más desinfección al alta de pacientes}

\section{A. Superficies}

Limpieza con agua y detergente de todas las superficies de la habitación, de arriba abajo y de dentro afuera, en el siguiente orden:

Paredes

Repisas

Cama, mesilla y armario

Aclarado con agua limpia.

Desinfección de superficies y mobiliario aplicando el desinfectante Germikill con la mopa humedecida.
B. Suelos

- Barrido húmedo y fregado del suelo de dentro hacia afuera.

- Limpieza con agua limpia para eliminar cualquier resto de detergente.

- Extender el desinfectante de dentro hacia fuera.

- Si la habitación dispone de un sistema de ventilación propio, éste deberá permanecer en funcionamiento mientras se realiza la limpieza y desinfección, evitando abrir puertas y ventanas.

- Mantener la puerta cerrada hasta su completo secado.

- El material utilizado se limpiará y desinfectará posteriormente, dejándolo sumergido durante 20 minutos en la solución clorada. Tras su limpieza se dejará secar.

\section{Importante}

El personal de enfermería debe comprobar que se ha efectuado correctamente la limpieza y desinfección.

La habitación se puede utilizar transcurridos después que 30 minutos después de la finalización del proceso, siempre y cuando paredes, superficies y suelos estén secos.

\section{REFERENCIAS}

1. STERIS Corporation. Antiseptics and Disinfectants: Activity, Action, and Resistance. Clin Microbiol Rev, 1999;12(1):147-179

2. APIC guideline for selection and use of disinfectants. Guidelines for infection control practice. AJIC 1996; 24(4):313-342.

3. Weinstein R. Chlorhexidine: expanding the armamentarium for infection control and prevention. CID 2008; 46:274-281.
4. Norma de antisépticos y desinfectantes Hospital del Trabajador de Santiago, 2004.

5. Norma $\mathrm{N}^{\circ} 3$ "uso de antisépticos y desinfectantes". Hospital base de Valdivia, 2008.

6. Norma $\mathrm{N}^{\circ} 2$ "uso de antisépticos y desinfectantes". Hospital Clinico de la Universidad de Chile, 2013. 